64

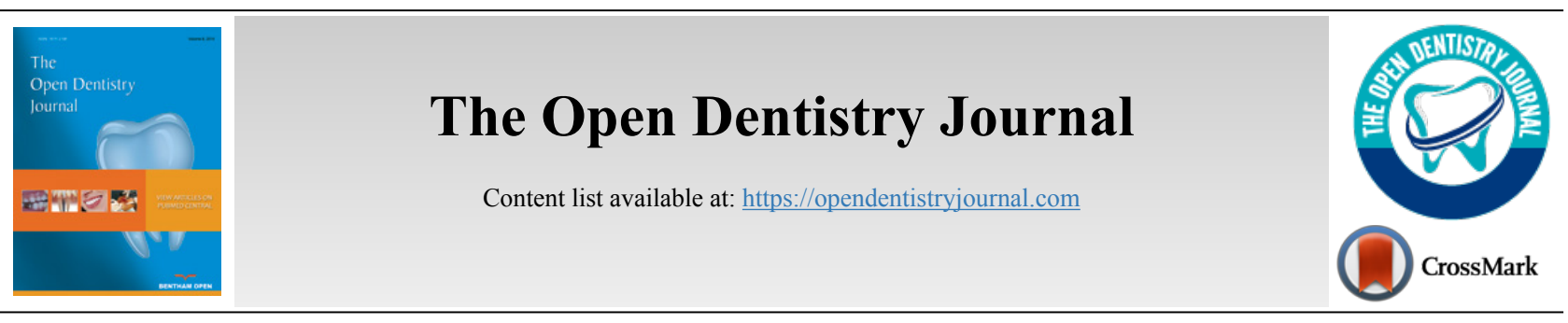

RESEARCH ARTICLE

\title{
The Saudi Infection Control Guidance for Re-opening Dental Services in Governmental and Private Sectors During Coronavirus Disease-2019 Pandemic
}

\author{
Ali AlAhdal ${ }^{1, *}$, Haila Al-Huraishi ${ }^{2}$, Ahmad Almalag $^{3}$, Adel Alrusayes ${ }^{4}$ and Saud M Orfali ${ }^{5}$ \\ ${ }^{1}$ Directorate of Dentistry, Makkah Health Affairs, Ministry of Health, Makkah, Saudi Arabia \\ ${ }^{2}$ Department of Orofacial Pain, Riyadh Specialized Dental Center, Ministry of Health, Riyadh, Saudi Arabia \\ ${ }^{3}$ Department of Endodontics, Hail Dental Center, Hail Health Affairs, Ministry of Health, Hail, Saudi Arabia \\ ${ }^{4}$ Department of Pediatric Dentistry, Preventive Programs and Training, General Directorate of Dentistry, Ministry of Health, Riyadh, Saudi Arabia \\ ${ }^{5}$ General Directorate of Dentistry, Ministry of Health, Riyadh, Saudi Arabia
}

\begin{abstract}
:
Objective:

Novel newly discovered coronavirus, also known as severe acute respiratory syndrome coronavirus-2, is a recently emerging virus that has been rapidly spreading globally since December 2019. Due to the vicinity inoro-dental treatment and aerosol production, people inside the dental office are at high risk of being infected with severe acute respiratory syndrome coronavirus- 2 . This guideline aims to protect the dental health-care workers during their plans to re-open and increasingly continue their routine services until further notice from their governing body.

Methods:

A panel of experts in dentistry and infection prevention and control reviewed the local and global research and guidelines related to infection prevention and control during coronavirus disease-2019, along with the re-opening guidance provided by different entities.

Results:

Such a document might either be adopted or adapted to any regional and international organization that wishes to use a revised professional guideline in infection prevention and control dental services.

Conclusion:

A careful re-opening plan should be developed and implemented, including strict infection control measures before resuming the dental practice.
\end{abstract}

Keywords: Dentistry, Dental infection control, Re-opening dental services, COVID-19 guideline, Dental guideline, Infection control.

\begin{tabular}{|l|l|l|r} 
Article History & Received: October 24, 2021 & Revised: January 05, 2021 & Accepted: January 07, 2021
\end{tabular}

\section{INTRODUCTION}

Novel newly discovered coronavirus, also known as severe acute respiratory syndrome coronavirus-2 (SARS CoV-2), is a newly emerging virus that has been rapidly spreading globally since December 2019. This type of coronavirus causes coronavirus disease-2019 (COVID-19) [1]. Transmission of SARS CoV-2 potentially occurs by direct contact with respiratory mucosa or conjunctivae. Basically, via secretions from the respiratory system by direct contact or through in-

\footnotetext{
* Address correspondence to this author at Directorate of Dentistry, Makkah Health Affairs, Ministry of Health Amena Bint Wahab Street, Alhamra, 24321 Makkah, Saudi Arabia; Tel:966567572600; E-mail: ali-alahdal10@homail.com
}

termediate body that touched contaminated surfaces, i.e., hands. However, airborne transmission is anticipated within aerosol-generating procedures (AGPs) $[2$ - 4]. Due to the vicinity in oro-dental treatment and aerosol production, people inside the dental office are at high risk of being infected with severe acute respiratory syndrome coronavirus- 2 .

The broad international distribution of SARS CoV-2 has impacted dental practice. Dental health-care workers (DHWs) have a high risk of transmission because of the face-to-face contact as the virus is significantly shed in the saliva $[5,6]$. Moreover, the asymptomatic transmission of the disease has been reported in the literature [7]. Accordingly, many dental clinics have been suspended from work and have only shifted to urgent treatment under stringent conditions. 
In late March 2020, the Ministry of Health (MOH) limited all dental providers to care only for dental emergencies. Besides, "Dental Emergency Protocol during COVID-19 Pandemic" was released by the General Directorate of Dentistry, $\mathrm{MOH}$, to highlight the safest-best practices in the present pandemic. Nowadays, The $\mathrm{MOH}$ began to consistently re-open some of the clinical services for usual conditions. In this guidance, the current distribution status of COVID -19 as well as the drawback of postponing management of dental patients, were considered. Furthermore, Infection control instructions that are accurate, well-planned, and well-trained are considered essential for such a reopening strategy to prevent COVID-19 outbreaks in dental settings.

\section{AIM}

This guideline aims to protect the DHWs during their plans to re-open and increasingly continue their routine services until further notice from their governing body. It is parallel with Infection Prevention and Control (IPC) documents that were previously issued by other institutions and organizations such as the Centers for Disease Control and Prevention (CDC) and American Dental Association or any other local guidelines. Therefore, they must be carefully read, understood, and applied.

To the best of our knowledge, our manuscript is the only local and international guideline that provides an objective visual triage scoring system and schematic actions for the dental specialty. This will provide a roadmap to categorize the patients and isolate the high-risk individuals before beginning the dental treatment. Thus, it offers an optimum infection control practice during the epidemic.

\section{METHODS}

A panel of experts in dentistry and infection prevention and control reviewed the local and global research and guidelines related to IPC during COVID-19 and the re-opening guidance provided by different entities. The instructions and evidence-based knowledge was taken into consideration during the development of this guideline.

\section{RESULTS}

Such a document might be adopted or adapted to any regional and international organization that wants to use a revised professional guideline for infection prevention and control for dental services during the COVID-19 pandemic.

\subsection{Dental Infection Control Practices in COVID-19 Pandemic}

IPC science was defined as measures that are encountered in the surroundings and through practical operations. They aim to stop and manage the spread, acquiring, and cross of infectious agents within the health-care industry [8]. Therefore, the specifically proposed IPC measures at the COVID-19 pandemic have to be escorted with all previously known standard precautions in a normal situation to provide full protection for the DHWs and patients. These measures include hand hygiene, PPE, covering high touchable surfaces. In this document,moreIPCmeasures are detailed and compelled, especially for the COVID-19 pandemic.

\subsubsection{Dental Health-care Workers Preparedness}

DHWs are advised to steadily continue their duties to ensure public health safety and prevent infection. Their awareness and education are fundamentals before restart running the dental facility. An evaluation of the adherence to the IPC guidelines is mandated. Sufficient training on the guidelines must be carefully planned, executed, and guaranteed. Facilities must ensure that all DHWs understand these guidelines and assess their capability to stick to them.

According to the local governing body instructions, dental facilities/clinics have to comply with their working hours. It is an absolute necessity to make sure that IPC guidelines in staff residencies are strictly applied. Including those for housekeepers, if any. The in-need maintenance has to be arranged and coordinated with companies to ensure their compliance with these roles.

A visual triage point at the facility entrance should be established. Employees suffering from these fever $\geq 38^{\circ} \mathrm{c}$, cough, sore throat and/or shortness of breath must not attend and have to report to the management to find medical care. They are not permitted back to duty without clearance from the medical side.

\subsubsection{Personal Protective Equipment (PPE)}

Usually, the safeguard gears against dentally-generatedaerosolized droplet nuclei are not recommended. However, it is mandatory to use the respiratory protection devices, e.g., nonoil resistant with $95 \%$ filtration capacity (N95) respirator or powered air-purifying respirator (PAPR) with other PPE for patients who score $>$ zero during the pandemic when AGPs are decided to be performed [9].

Facilities have to register the fitting test and training of N95 respirators for their DHWs during the fitting test. The Occupational Safety and Health Administration (OSHA) and/or National Institute for Occupational Safety and Health (NIOSH) are agencies that approve the specifications for N95 respirators. Certified N95 should be used in health-care facilities to assure protection. Alternatively, the third class Filtering Facepiece Respirator (FFP3) can be used as a replacement of the N95 respirator, which follows the standard for the European Committee for Standardization (CEN) EN 149:2001+A1:2009.

NB: Users of PPE should be instructed to take them off normally in the clinic except for N95 or PAPR. They must be removed outside the clinic and discarded in acontaminatedwastecontainer [10].

\subsubsection{Air Control}

AGPs for patients are better to be performed under one of the following air control options, particularly for suspected patients or confirmed for COVID-19:

A- Heating, ventilation, and air conditioning "HVAC" system with negative pressure within dental settings [2].

B- Airborne infection isolation room (AIIR) in a hospital setting provided with portable dental gear. 
C- Portable high-efficiency particulate air "HEPA" filter in the dental clinic.

\subsubsection{Decontamination of Dental Settings}

Thorough terminal decontamination should follow dental procedures for all surfaces. Meanwhile, the postponing decontamination process is obligatory prior to reuse the dental clinic to eradicate aerosols as the surroundings stay contaminated due to AGPs [11 - 13]. The guidance for timelaps before begin decontamination is dependent on the type of air control (Table 1) $[3,9,14]$. It is recommended to use disposable mops and non-woven cloths incorporated in a fresh detergent or detergent combined with low-level disinfectants for non-clinical surfaces. For clinical surfaces, intermediatelevel disinfectant wipes or sprays are. Be sure to put on full PPE [with regular masks] during decontamination. Some of the decontamination intermediate-level chemicals suggested in the literature are listed in Table 2 [11].

Table 1. Guidance for time-lapse before beginning decontamination.

\begin{tabular}{|c|c|}
\hline Type of Air Control & $\begin{array}{c}\text { Recommended Time to postpone } \\
\text { Decontamination }\end{array}$ \\
\hline Negative pressure HVAC* & At least 20 minutes \\
\hline HEPA-filtered Room** & $\begin{array}{c}\text { Follow manufacturer's instruction for } \\
\text { complete air filtration }\end{array}$ \\
\hline Neutrally air-ventilated room & At least one hour \\
\hline \\
*HVAC: heating, ventilation, and air conditioning. \\
*HEPA: high-efficiency particulate air.
\end{tabular}

Table 2. Guidance for disinfection chemicals for SARS CoV-2.

\begin{tabular}{|c|c|}
\hline Intermediate-level Chemical formula & Dilution Rate \\
\hline Ethyl Alcohol & $62 \%-71 \%$ \\
\hline Hydrogen peroxide [H2O2] & $0.5 \%$ \\
\hline 5\% sodium hypochlorite* & $\begin{array}{c}0.1 \%[1,000 \text { of chlorine] } \\
1 \text { volume of } 5 \% \text { sodium } \\
\text { hypochlorite to } 49 \text { volumes of } \\
\text { water }\end{array}$ \\
\hline [50,000 part per million chlorine] & Cause corrosion to the metallic surfaces in such concentration.
\end{tabular}

\subsubsection{Engineering Control}

It is important to eliminate the hazardous conditions to preserve DHWs by a barrier between the staff and the hazard by taking advantage of technology or innovation. For instance, expelling the airborne emissions by exhausted-local ventilation. The most important thing is that technologies and innovations do not intervene with the original procedure, comfort, and outcome. Rather, they must be of substantial impact on safeguarding the workers' health and preventing hazards. In the absence of unequivocal evidence to back up these measurements' significance, their clinical performance in reducing aerosols is worthy of being referred to.

\subsubsection{Respiratory Triage and IPC Management Protocol}

Respiratory triage aims to early detect persons who are potentially respiratory infectious and therefore decrease the chance of disseminating the infection inside the facility. A visual triage scoring form [respiratory triage checklist] is being used as issued from Saudi Center for Disease Prevention and Control (Weqaya).

Depending on the scores, the patients are considered as high risk of transmitting a respiratory disease, including COVID-19 if score $\geq \mathbf{4}$, moderate risk if score between $\mathbf{1}$ and $\mathbf{4}$, finally low risk if score $=\mathbf{0}$.

\subsubsection{Two types of Triaging could be Applied for Dental $\underline{\text { Setting }}$}

\section{a- Triaging by Telephone [2]:}

In case, the patient called the dental clinic for an appointment; in this case, a trained dental assistant will fill the triage scoring form Appendix 1, and ask the patient if he has any dental emergency after that inform him if he can come to the dental clinic for evaluation.

\section{b-Triaging upon Arrival of the Patient:}

A well-trained dental assistant will fill the triage scoring form Appendix 1, and the patient will be asked if he has any respiratory symptoms then the triage nurse should measure the patient's body temperature using a non-contact forehead thermometer [15].

Illustration of IPC management protocol according to the patients given scores as per the respiratory triage checklist for COVID-19 can be found in Fig. (1).

\subsubsection{Additional Measures and Instructions}

- When AGPs started, effort should be made to finish the aim of the procedure. Upon completion, single-use PPE must be put in infectious waste bags. Consideration to operate two clinics, whenever feasible, is advisable.

- For those who score $\geq 4$, oral radiographs are best to be postponed or adhere to the radiology department guidelines for extra-oral radiographs. If the patient's case score $<4$ or score of zero, instruct the patient to doHH and put on a regular mask for taking anorthopantomogram.

- Using manual instrumentation is preferred and should be prioritized over the use of dental turbines.

- Whenever possible, use a rubber dam or any other appropriate isolation method, e.g., dry shield and isolite,along side high volume suction to reduce aerosol or splatter.

- The 4-handed technique is always useful for the management of aerosolization or splatter.

- Use High-volume evacuators appropriately, i.e., as near as it could be to the operation area within $15 \mathrm{~mm}$. It effectively reduces the aerosols up to $90 \%$ immediately at the operation area [16].

- Backflow could occur when the patient closes his mouth on a saliva ejector, posing a risk of cross-contamination.

- Use resorbable sutures whenever possible to eliminate the need to suture removing appointments.

- Decrease the application of the 3-in-1 syringe to the minimum. Droplets might be generated as the water and air are 
forced through its narrow tip.

- Patients are eligible to receive dental treatment normally if they are cleared from the COVID-19.

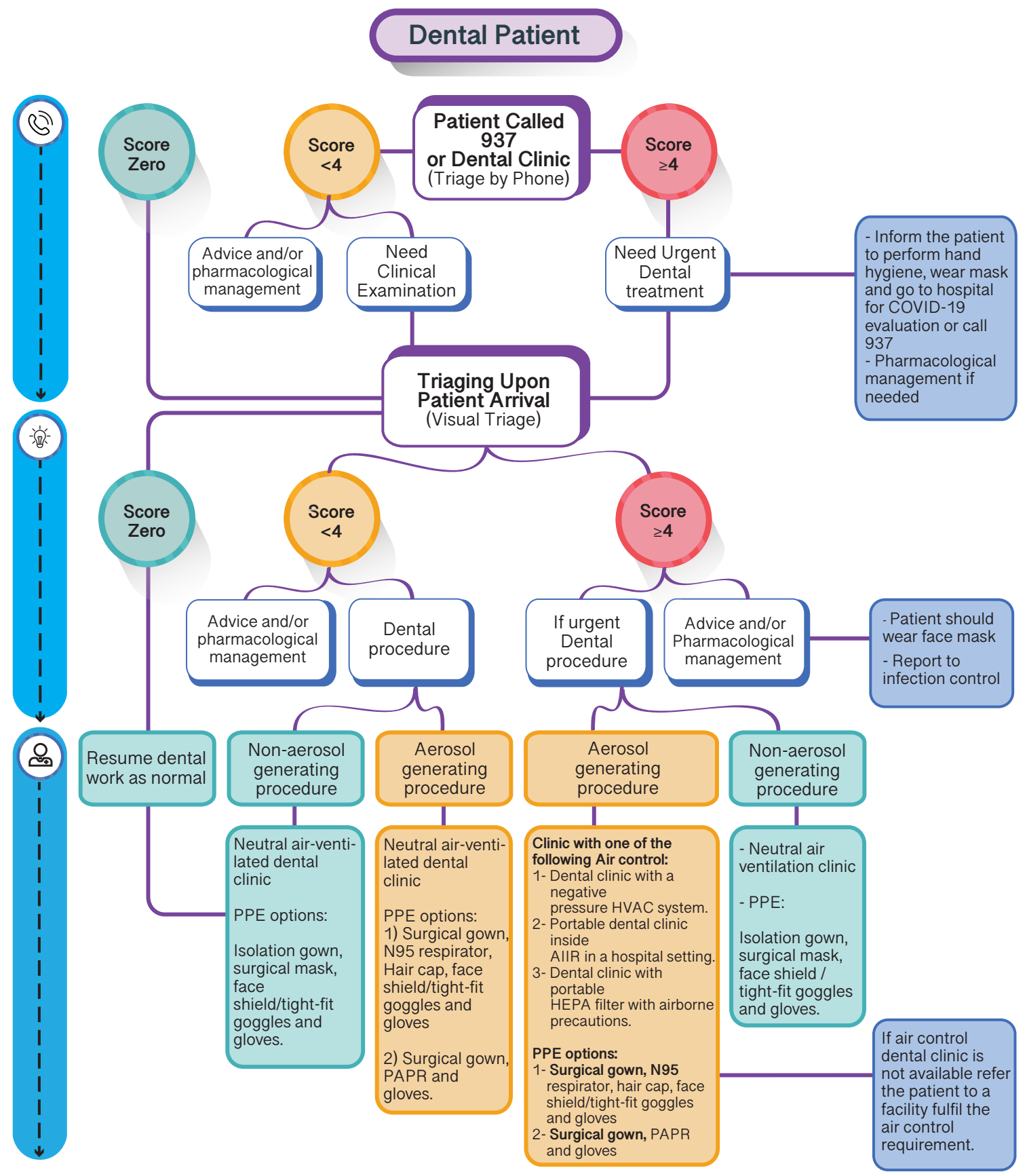

Fig. (1). Illustration of the respiratory triage and IPC management protocol according to the patients given scores for COVID-19.

COVID-19: Coronavirus disease-2019

PPE: Personal Protective Equipment

HEPA: High-Efficiency Particulate Air

AIIR: Airborne infection isolation room

HVAC: Heating, Ventilation, and Air Conditioning 


\section{DISCUSSION}

This guideline aims to help to protect all dental health facilities and DHWs during their plans to re-open and resume their routine services until further notice from their governing body. Different regulatory bodies might benefit from this document by adopting our guidance to their local system. In another way, entities could adapt to such guidelines for their re-opening plans. As for the task force percentage, each system/regulatory body might have its own decision. For example, the Center for Disease Control and Prevention (CDC) does not require any workforce limitation during the reopening of dental service. Unlike the Saudi national guideline, $50 \%$ of the task force is recommended per the whole national policy.

Though there are no particular recommendations for the sterilization process during COVID-19, DHWs should practice good care to prevent any contact with contaminated instruments and sharp injuries. Indirect transmission of the SARS CoV-2 is still a risk after hazardous exposure to such instruments and devices holding the virus.

Using engineering control devices to reduce the contamination of the surrounding air by decreasing the number of floating aerosols is highly recommended. However, attention should be paid if they are going to be used as a substitute for the medical HEPA filter as these devices are equipped with a HEPA filter to capture the tiny microorganisms. Only devices that match the capacity of air recirculation and the medical HEPA filter's filtering ability are to be used as a replacement.

Since the distribution of COVID-19 is not equal in the whole regions of Saudi Arabia, risk including health and general physical conditions, medical history and demographics of the dental patients should be considered. DHWs with good general health care better to be thought of to provide care for patients. Moreover, consideration to delay elective operations for older patients [65+] and patients with a compromised immune system. Meanwhile, healthy patients without urgency are encouraged to delay dental treatment and maintain optimal oral hygiene.

\section{CONCLUSION}

COVID-19 is potentially a high-risk disease to be transmitted through dental practice due to aerosols generating procedures. A careful re-opening plan should be developed and implemented, including strict IPC measures before resuming the dental practice.

\section{ACRONYMS AND NOMENCLATURE}

- Neutrally air-ventilated room: this room is provided with an air-conditioner or natural

- ventilation. A single-directed airflow was not invented intentionally across the room.

- HEPA Filter: high-efficiency particulate air (HEPA), alternatively named high-efficiency particle absorption and highly efficient particle capture. Generally standardized, a HEPA air filter must remove at least
$99.95 \%$ or $99.97 \%$ particles $>=0.3 \mu \mathrm{m}$ according to the European Standard and ASME, U.S. DOE, respectively. Filtration efficiency is getting high for particle dimensions around the size of $0.3 \mu \mathrm{m}$.

- PAPR: powered air-purifying respirator is a batterypowered air pumper that forces flow positively within the filter system to a headcover. The kind of filter system required for the PAPR is specified according to the magnitude of airborne pollutants [17]. It is used by those who do not find a particular fit-tested N95, did not fit for the N95 fitting test, or who has a beard.

- Aerosols: a blend of various sizes of particles. These are classified as droplet nuclei $[\leq 10 \mu \mathrm{m}]$, droplet $[\leq 50$ $\mu \mathrm{m}]$, and splatter $[>50 \mu \mathrm{m}]$. The majority of the aerosols produced in the dental office are excessively small $[0.5$ to $5 \mu \mathrm{m}][15,18,19]$.

- Aerosol-Generating Procedures [AGPs]: operations able to produce dangerous tiny particles $[\leq 10 \mu \mathrm{m}]$. A high risk of transmission of viruses was linked with AGPs [e.g., SARS-CoV and MERS-CoV]. Such operations include cardiopulmonary resuscitation, the use of dental turbines, nasopharyngeal swabbing, noninvasive ventilation, tracheotomy, and tracheal intubation.

- Standard Precautions: infection control practices used to evade disease transmission can be gained by handling or contacting mucous membranes, non-intact skin [including rashes], blood, and body fluids [20].

- Transmission-Based Precautions: precautions to be practiced in conjunction with standard precautions for specific infection types or infectious agents. These extra precautions are needed to avoid transmission [20].

- Clinical contact surfaces: surfaces that are touched repeatedly during patient care. Contamination with blood and other body fluids might quickly occur, and then infectious agents might pass to instruments, devices, hands, or gloves [20]. Appropriate treatment of these surfaces is desired before the care of the following patient.

- Housekeeping surfaces: those surfaces that do not include hands or devices used for dental procedures [e.g., floors, walls, and sinks] [21].

- Emergent care: all probable life-threatening situations which require immediate intervention in the hospital emergency department. Emergencies include uncontrolled bleeding, sizeable facial swelling, and trauma potentially jeopardizing the patient's airway, significant infection (e.g., space infection, cellulitis).

- Urgent dental care concentrates on the management of acute or uncontrolled signs and symptoms that will not be subsided by the patient and demanding a visit to the dental facility.

- Non-urgent dental care: involves regular and elective clinical procedures.

- Advice care: symptoms that are not severe- are managed on distance by the dentist (on the phone), providing advice and management with analgesics and antimicrobials. 


\section{AUTHORS' CONTRIBUTION}

Orfali selected and composed the committee to design and develop the current guideline. He performed all of the administrative requirements and offered facilitation to the committee. Alrusayes and orfali provided the committee with support in the scientific materials, writing the introduction, and the $2^{\text {nd }}$ and $3^{\text {rd }}$ "final" revisions, respectively. AlAhdal, Almalaq, and Al-Huraishi structured the guideline by reviewing the literature and international guidelines then writing up the "Dental Infection Control Practices in COVID19 Pandemic" section. The same group completed the $1^{\text {st }}$ revision of the manuscript.

\section{ETHICS APPROVAL AND CONSENT TO PARTI- CIPATE}

Not applicable.

\section{HUMAN AND ANIMAL RIGHTS}

No animals/humans were used for studies that are the basis of this research.

\section{CONSENT FOR PUBLICATION}

Not applicable.

\section{AVAILABILITY OF DATA AND MATERIALS}

The data sets used during the current study can be provided from the corresponding author [A.A], upon reasonable request.

\section{FUNDING}

None.

\section{CONFLICT OF INTEREST}

The authors declare no conflict of interest, financial or otherwise.

\section{ACKNOWLEDGEMENTS}

The authors are grateful to Dr. Ali S. Alrumihkan, Dr. Fuad Al-Malki and Dr. Saeed B. Alzahran for their valuable assistance and positive comments during the revision phase.

\section{APPENDIX}

Appendix 1. A visual triage scoring form (Respiratory Triage Checklist) issued by saudi center for disease prevention and control (Weqaya).

\begin{tabular}{|c|c|c|}
\hline \multicolumn{3}{|l|}{ Respiratory Triage Checklist } \\
\hline Date: & \multicolumn{2}{|l|}{ Time: } \\
\hline Name: & \multicolumn{2}{|l|}{ Hospital: } \\
\hline \multicolumn{3}{|l|}{ Circle the number reflecting the patient's condition (exposure and clinical picture) and calculate the final score: } \\
\hline Risks for Acute Respiratory Illnesses & \multicolumn{2}{|c|}{ Score } \\
\hline A. Exposure Risks & \multicolumn{2}{|c|}{ Any Patient $\{$ Adult or Pediatric) } \\
\hline A history of travel broad during the 14 days prior to symptom onset. & \multicolumn{2}{|c|}{-} \\
\hline OR & \multicolumn{2}{|c|}{-} \\
\hline $\begin{array}{l}\text { Visiting or being resident of a high-risk area for COVID-19 in the kingdom during the } 14 \text { days prior to symptom } \\
\text { onset*. }\end{array}$ & \multicolumn{2}{|c|}{ - } \\
\hline OR & \multicolumn{2}{|c|}{-} \\
\hline A close physical contact with a confirmed case of COVID-19 or MERS-CoV in the past 14 days. & \multicolumn{2}{|c|}{-} \\
\hline OR & \multicolumn{2}{|c|}{3} \\
\hline An exposure to camel or camel's products (direct or indirect**) in the past 14 days. & \multicolumn{2}{|c|}{-} \\
\hline OR & \multicolumn{2}{|c|}{-} \\
\hline Working in a healthcare facility. & \multicolumn{2}{|c|}{-} \\
\hline B. Clinical Signs and Symptoms and Medical History & Pediatric & Adult \\
\hline 1. Fever or recent history of fever. & 1 & 2 \\
\hline 2. Cough (new or worseni ng). & 1 & 2 \\
\hline 3. Shortness of breath (new or worsening). & 1 & 2 \\
\hline 4. Nausea, vomiting,and/or diarrhea. & - & 1 \\
\hline 5. Chronic renal failure, CAD/heart failure, immunocompromisd patient. & - & 1 \\
\hline Total Score & - & - \\
\hline
\end{tabular}

* As determined and announced by the Ministry of Interior or Ministry of Health. Updated regularly on: www.covid19.cdc.gov.sa/

** Patient or household

\section{REFERENCES}

[1] Li Q, Guan X, Wu P, et al. Early transmission dynamics in Wuhan, China, of novel coronavirus-infected pneumonia. N Engl J Med 2020; 382(13): 1199-207. [http://dx.doi.org/10.1056/NEJMoa2001316] [PMID: 31995857]

[2] Ather A, Patel B, Ruparel NB, Diogenes A, Hargreaves KM. Coronavirus Disease 19 [COVID-19]: Implications for clinical dental care. J Endod 2020.
[3] Su J. Aerosol transmission risk and comprehensive prevention and control strategy in dental treatment Zhonghua kou qiang yi xue za zhi= Zhonghua kouqiang yixue zazhi= Chinese $J$ Stomat 2020; 9;55(4): 229-34.

[4] Wu D, Wu T, Liu Q, Yang Z. The SARS-CoV-2 outbreak: What we know. Int J Infect Dis 2020; 94: 44-8. [http://dx.doi.org/10.1016/j.ijid.2020.03.004] [PMID: 32171952]

[5] To KK-W, Tsang OT-Y, Yip CC-Y, et al. Consistent detection of 2019 novel coronavirus in saliva. Clin Infect Dis 2020; 71(15): 841-3. 
[http://dx.doi.org/10.1093/cid/ciaa149] [PMID: 32047895]

[6] Wax RS, Christian MD. Practical recommendations for critical care and anesthesiology teams caring for novel coronavirus [2019-nCoV] patients Canadian J Anes 2020; 1-9.

[7] Rothe C, Schunk M, Sothmann P, et al. Transmission of 2019-nCoV infection from an asymptomatic contact in Germany. N Engl J Med 2020; 382(10): 970-1.

[http://dx.doi.org/10.1056/NEJMc2001468] [PMID: 32003551]

[8] AlAhdal A, Bahlas R, Mahfouz A, AlAhdal E, Aboalshamat K. Knowledge assessment of the dental healthcare workers regarding sterilization integrity of dental instruments. Int J Dent Oral Health 2019; 5. [4].

[9] Guideline and Guidance for COVID-19 - Annex 1: infection prevention and control in urgent dental care settings during the period of COVID-19 Scotland: Health Protection Scotland 11 April 2020.

[10] Available from: APIC_DosDonts_Respirators_hiq.pdf.

[11] Ge ZY, Yang LM, Xia JJ, Fu XH, Zhang YZ. Possible aerosol transmission of COVID-19 and special precautions in dentistry. $J$ Zhejiang Univ Sci B 2020; 21(5): 361-8.

[http://dx.doi.org/10.1631/jzus.B2010010] [PMID: 32425001]

[12] Available from: ADA_COVID_Int_Guidance_Treat_Pts.pdf.

[13] Available from: ADA_Int_Guidance_Mgmt_EmergUrg Dental COVID19.pdf.

[14] Apic text of infection control and epidemiology the association for professionals in infection control and epidemiology; $2014 \mathrm{p}$ Chapter
18 - Isolation Precautions. 2014; pp. 4-3

[15] James R, Mani A. Dental Aerosols: A Silent Hazard in Dentistry! Int J Sci Res 2016; 5: 1761-3.

[16] Narayana TV, Mohanty L, Sreenath G, Vidhyadhari P. Role of preprocedural rinse and high volume evacuator in reducing bacterial contamination in bioaerosols. J Oral Maxillofac Pathol 2016; 20(1): 59-65.

[http://dx.doi.org/10.4103/0973-029X.180931] [PMID: 27194863]

[17] Bollinger NJ. NIOSH respirator selection logic US Department of Health and Human Services, Public Health Service, Centers for Disease Control. National Institute for Occupational Safety and Health 2004.

[18] Harrel SK, Molinari J. Aerosols and splatter in dentistry: A brief review of the literature and infection control implications. J Am Dentl Associat 2004; 1;135(4): 429-37.

[19] Chartier Y, Pessoa-Silva C. Natural ventilation for infection control in health-care settings. World Health Organization 2009.

[20] Siegel JD, Rhinehart E, Jackson M, Chiarello L, Committee HCICPA. 2007 guideline for isolation precautions: preventing transmission of infectious agents in health care settings. Am J Infect Control 2007; 35(10)(Suppl. 2): S65-S164.

[http://dx.doi.org/10.1016/j.ajic.2007.10.007] [PMID: 18068815]

[21] Kohn WG, Collins AS, Cleveland JL, Harte JA, Eklund KJ, Malvitz DM. Guidelines for infection control in dental health-care settings. MMWR Recomm Rep 2003; 52(RR-17): 1-61.

\section{(C) 2021 AlAhdal et al.}

This is an open access article distributed under the terms of the Creative Commons Attribution 4.0 International Public License (CC-BY 4.0), a copy of which is available at: https://creativecommons.org/licenses/by/4.0/legalcode. This license permits unrestricted use, distribution, and reproduction in any medium, provided the original author and source are credited. 